points save one, which, as he truly observes, is "seemingly capable of settlement by scientific inquiry." This point simply is as to whether variation in plants and animals is promiscuous (not "lawless") or is restricted to beneficial lines.

Now with reference to this point, I observed in my first letter (NATURE, vol, xxvii. p. 362) that if variation is promiscuous it is only the favourable variations that are able to survive, and hence the sole ground of entertaining natural selection as an agency in the process of evolution ; but that, on the other hand, if it could be shown that variations always take place exclusively in the directions required for a development of the adaptations, so as to leave no room for the operation of natural selection, then the evidence of design as deduced from the theory of evolution would become comparable with that evidence as deduced from the theory of special creation. But $\mathrm{I}$ also pointed out that " the burden of proof lies with the natural theologian to show that there has been some such intelligent guidance of the variations, not with the evolutionist to show cause why there may not have been such guidance." And now I understand Prof. Gray accepts this as a correct statement of the case, observing in his last letter that, if variation is promiscuous, "then no doubt the theory of natural selection may be "the substitute of the theory of special design,' so as to efface that evidence of underlying intelligence which innumerable and otherwise inexplicable adaptations of means to ends in nature was thought to furnish. If it is not so, then the substitute utterly fails."

It is most satisfactory to me that the issue bas thus been clearly reciuced to a simple matter of scientific observation, and I may add that $I$ am much interested to find that a naturalist of such high standing as Prof. Gray still holds to the view that, "so far as observation extends, it does not warrant the supposition of omnifarious and aimless variation." Of course, if I had not believed in "aimless variation" as of universal occurrence in organic nature, I should never have supposed that the theory of evolution by natural selection could in any u ay touch the theory of special design; but finding that my fundamental belief in this matter is still open to question by so esteemed an authority as Prof. Gray, and observing that we are here upon the gruund of a purely scientific question, I should like to say a few words in justification of this belief.

No one has attended to the subject of variation with a tenth part of the care that was bestowed upon it by Mr. Darwin, and no one has been gifted with a better judgment in matters of this kind. I shall therefore restrict myself to giving a brief outline of his matured opinion upon the subject.

Everywhere he speaks of variation as promiscuous or aimless, but never as "lawless," and only under a carefully guarded meaning as accidental. That is to say, he has no doubt that every variation is due to causes, though not of a teleological kind. Of these causes he reyards changes of environment as highly important; but nevertheless he is inclined to lay less weight on these " than on a tendency to vary due to causes of which u e are quite ignorant." 1 But with reference to variations not taking place exclusively in beneficial lines he says: "As man has domesticated so many animals and plants belonging to widely different classes, and as he certainly did not choose with prophetic instinct those species which would vary most, we may infer that all natural species, if exposed to analogous conditions, would, on an average, vary to the same degree. . . We have abundant evidence of the constant occurrence under nature of slight individual differences of the most diversified kinds; and we are thus led to conclude that species have generally originated by the natural selection of extremely slight differences; . . although each modification must have its own exciting canse, and though each is subjected to law, yet we can so rarely trace the precise relation between cause and effect, that we are tempted to speak of variations as if they arose spontaneously. We may even call them accidental, but this must be only in the sense in which we say that a fragment of rock dropped from a height owes its shape to accident. . . . If an architect were to rear a noble and commodious edifice without the use of cut stone, by selecting from the fragments at the base of a precipice wedgeformed stones for his arches, elongated stones for his lintels, and flat stones for his roof, we should admire his skill and regard him as the paramount power. Now the fragments of stone, though indispensable to the architect, bear to the edifice the same relation which the fluctliating variations of organic beings bear to the varied and admirable structures ultimately acquired by their modified descendants. ... The shape of the fragments at the

\footnotetext{
"Origin of Species," 6th edition, p. ro7.
}

base of our precipice may be called accidental, but this is not strictly correct; for the shape of each depends on a long sequence of events, all obeying natural laws; . . . but in regard to the use to which the fragments may be put, their shape may be strictly said to be accidental. . . . Can it be reasonably maintained that the Creator intentionally ordered, if we use the word in any ordinary sense, that certain fragments of rock thould assume certain shapes, so that the builder might erect his edifice? If the various laws which have determined the shape of each fragment were not predetermined for the builder's sake, can it be maintained with any greater probability that $\mathrm{He}$ specially ordained for the sake of the breeder each of the innumerable variations in our domestic animals and plants;-many of these variations being of no service to man, and not beneficial, far more often injurious, to the creatures themselves? Did $\mathrm{He}$ ordain that the crop and tail-feathers of the pigeon should vary in order that the fancier might make his grotesque pouter and fantail breeds? Did He cause the frame and mental qualities of the dog to vary in order that a breed might be formed of in. domitable ferocity, with jaws fitted to pin down the bull for man's brutal sport? But if we give up the principle in one case, -if we do not admit that the variations of the primeval dog were intentionally guided in order that the greyhound, for instance, that perfect image of symmetry and vigour, might be formed, - no shadow of reason can be assigned for the belief that variations, alıke in nature and the result of the same general laws, which have been the groundwork through natural selection of the formation of the most perfectly adapted animals in the world, man included, were intentionally and specially designed. However much ve may wish it, we can hardly follow Prof. Asa Gray in his belief 'that variation has been led along certain beneficial lines,' like a stream 'along definite and useful lines of irrigation." "' 1

I could give a number of other quotations to the same general effect from the writings of $\mathrm{Mr}$. Darwin, but I think these are enough to show, as I have said, that if there is any evidence of variations being determined in special and beneficial lines, it now lies with the teleologist to adduce such evidence. If this could be done it would be a matter of immense importance, both from a scientific and a speculative point of view, seeing that on the scientific side it would be subversive of the whole theory of natural selection, and on the speculative side would therefore leave us where we were before the publication of the "Origin of Species." But at present the whole weight of such scientific evidence as we have appears $t_{1}$ me unquestionably opposed to Prof. Gray's statement that, "so far as observation extends, it does not warrant the supposition of omnifarious and aimless variation."

George J. Romanes

\section{Carson Footprints}

IN NA URE (vol. xxvii. p. 578) which I have just seen, the Duke of Argyll calls your attention to the so-called human footprints uncovered in the prison yard at Carson, Nevada. I have carefully examined these tracks, and read a paper on the subject before the California Academy of Science, August 27, 1882. Unfortunately the Proceedings of the Academy have not yet been published, though copies of the several papers on this subject have been printed and privately distributed. Perhaps a brief account of these tracks will be interesting to your readers.

The nearly horizontal strata in which they occur consist of beds of sandstone with thin layers of fine shale. The track layer, which is one of these latter, has been uncovered over an are $z$ of nearly two acres, and forms the floor of the prison yard, while the stone removed has been used to build the prison. In the course of the excavation a number of fossils have been found, among which the most important are the jaws and teeth of an elephant, probably E. Americanus, and two species of horse, Equns Pacificus and occidentalis; some freshwater shells, all of recent species, have also been found. The age of the deposit seems to be that of the "Equus beds" of American geologists, which by some are put in the uppermost Pliocene, and by others in the lowest Quaternary. It is probably a transition between the two.

The whole surface of the shale exposed in the prison yard is literally covered with tracks of many kinds, but the mud was so soft when the tracks were made that the nature of many of them can only be guessed. Some were probably those of a horse; some probably of a wolf; some certainly of a deer; I "Variations of Animals and Plants under Domestication." Second edition, vol. ii. pp. $401-2,410,4 \times 6,426-8$. 
many were those of long.legged wading birds. But the most interesting are those of the Mammoth and the problematical so-called human tracks. About the Mammoth tracks there can be no doubt. Some of these were uncovered by blasting in my presence; round basin-shaped impressions, 5 inches deep and 22 inches across, and occurring in regular alternating series, the hind-foot tracking almost perfectly with the fore-foot. The nature of the so-called human tracks, however, is far more doubtful. These occur in several regular alternating series of 15-20. In size they are $18-20$ inches long, and 8 inches wide. In shape they are many of them far more curved than the human track, especially in soft mud. The stride is $2 \frac{1}{2}$ to 3 feet, and even more. The outward turn of the track is in many cases greater than in human tracks, especially in soft mud. But the most remarkable thing about them on the human theory is the straddle, i.e. the distance between the right and left series. This I found to be 18 and even 19 inches, which was fully as great as that of the mammoth tracks. This is probably the greatest objection to the human theory. On the other hand, the great objection to the quadrupedal theory is the apparent singleness of the tracks, and the absence of claw-marks. But it must be remembered that the tracks are deep, and the outlines somewhat obscure, and also that the mammoth tracks, on account of tracking of hind with fore-foot, are in most cases, though not always, single.

After careful examination for several days, the conclusion I came to was that the tracks were probably made by a large plantigrade quadruped, most likely a gigantic ground-sloth, such as the Mylodon, which is found in the Quaternary, or the Morothenium, which is found in the upper Pliocene of Nevada. The apparent singleness, the singular shape, and the large out. ward turn of the tracks I attribute to the imperfect tracking of hind and fore-foot on the same side, while the absence of clawmarks was the result of the clogging of the feet with mud.

This view seems to me most probable, ${ }^{1}$ but many who have seen the tracks think them human, and I freely admit that there is abundant room for honest difference of opinion. On any theory the tracks are well worthy of scientific attention.

Berkeley, California, May I2 JOSEPH LE CONTE

\section{Cloudiness of Aquarium}

CAN you tell me the reason why the water in my fresh water aquarium will not remain clear, but becomes cloudy throughout in a few days after filling.

The aquarium in question holds about twelve gallons of water, It stands in a window facing north. I have in the water two or three water-plants, among them a water-aloe. At the bottom are small gravel stones, which have been thoroughly washed before using. Floating on the surface for the benefit of a few newts is a piece of virgin cork, on which is placed some carpet moss. I had a dozen minnows and four newts to begin with, but nine of the minnows and two of the newts have died, manifestly from the fouling of the water.

The framework of the aquarium is iron, with a slate floor. The glass sides are fixed with red lead. There is a copper tube for overflow purposes, which was inserted when a fountain was used in the centre. This has now been removed and the water is stagnant.

It is now some years since I have kept an aquarium, and I camot divine the reason for the above-mentioned cloudiness of the water. I shall be much obliged if you or some of your correspondents will help me.

$\mathrm{X}$. May 9

So far as I can judge from "X's" description, the cloudiness of the water in his aquarium is due to the abnormal development of some unicellular algal (Palmellaceæ) or to the prolific spore-production within it of one of the filamentous forms (Confervaceæ). This may be obviated by screening the back of the tank from the access of light. Possibly "X" may find on examination that the cistern whence he obtains his supply has been left uncovered, and that the intruding algal has established itself and entered upon the reproductive process in that position. In that case he should either $\mathrm{i}$-olate the water he requires in a dark place for a week or so, when the spores will die, or obtain his supply from a purer source. An investigation with a high po ver of the microscope of the turbid water complained of will ${ }^{x}$ Views similar to my own have recently been expressed by Prof. Marsh and by G. K. Gilbert. speedily determine whether the explanation here suggested is the correct one. By way of illustration, I may mention that the water of the ornamental pond in the centre of the Horticultural Gardens, supplied clear and bright shortly before the opening of the Fisheries Exhibition, had assumed within a few days and still retains the colour and consistency of green-pea soup through the rapid development, under the action of light, of a unicellular cryptogam in the manner above described.

W. SAVILLE KeNT

\section{Singing, Speaking, and Stammering}

REFERRING to the letters in NATURE (vol. xxvii. p. 580 ) on my classification of vowel sounds, allow me to explain :-

The classificalion given in the "Principles of Elocution" (4th $\epsilon d ., 1878$ ) was retained from the earlier editions of that work, because of the difficulty, or impossibility, of exhibiting the complete vowel system of visible speech without V.S. symbols. For the purposes of the book on Elocution, the latter were not required; but a note (on p. 36) immediately preceding the "General Vowel Scheme" explains the basis of the complete classification developed in visible speech.

As you have given an abstract of my classification, quoted by Dr. Stone from "Principles of Elocution," I shall be glad if you will show your readers the following abstract of the visible speech classification :-

\section{Classification of Vowels in Visible Speech}

Nine Lingual positions yield

9 Primary vowels .

Each Primary vowel yields a "Wide" variety by faucal expansion $=9 \mathrm{Wide}$ vowels

Each Lingual vowel yields a "Round" variety by

labial contraction ........

$$
\begin{gathered}
=\begin{array}{c}
18 \text { Lingual } \\
\text { vowels. }
\end{array} \\
=36 \text { Normal } \\
\text { vowels. }
\end{gathered}
$$

Each Normal vowel yields a possible variety by higher, lower, broader, or narrower formation $=36+144=a$ total of 180 vowels.

The mutual relations of the different sounds may be exhibited

\begin{tabular}{|c|c|c|c|c|c|c|}
\hline & \multicolumn{6}{|c|}{ Lingual. } \\
\hline & \multicolumn{3}{|c|}{ Primary. } & \multicolumn{3}{|c|}{ Wide. } \\
\hline & Back. & Mixed. & Front. & Back. & Mixed. & Front. \\
\hline High & 7 & 4 & I & 7 & 4 & I \\
\hline Mid & 8 & 5 & 2 & 8 & 5 & 2 \\
\hline Low & 9 & 6 & 3 & 9 & 6 & 3 \\
\hline
\end{tabular}
in this way :-

\begin{tabular}{|c|c|c|c|c|c|c|}
\hline & \multicolumn{6}{|c|}{ LABIO-LINGUAL. } \\
\hline & \multicolumn{3}{|c|}{ Primary. } & \multicolumn{3}{|c|}{ Wide. } \\
\hline & Back. & Mixed. & Front. & Back. & Mixed. & Front. \\
\hline High & 7 & 4 & I & 7 & 4 & I \\
\hline Mid & 8 & 5 & 2 & 8 & 5 & 2 \\
\hline Low & 9 & 6 & 3 & 9 & 6 & 3 \\
\hline
\end{tabular}

In this arrangement, each No. 1, No. 2, No. 3, \&c., in the four sets is formed from one and the same lingual position. These relations are plainly exhibited in the symbuls of visible speech. They cannot be shown by ordinary letters, but the use of numbers, as above, may make the arrangement clear to those who are not acquainted with visible speech.

Washington, D.C., May $\mathbf{2} 2$

Alex. Melville Bell

\section{On the Cold in March, and Absence of Sunspots}

I WAs travelling when Dr. Woeikof's letter appeared in NATURE (vol. xxviii. p. 53), and could not sooner reply to his criticisms on my communication (vol. xxvii. p. 551), "Unprecedented Cold in the Riviera-Absence of sunspots." Let me first remark that I do not go so far as to "ascribe (as Dr. Woeikof says that I do) the great cold of March, I883, at the 